\section{Adenocarcinoma arising in a mucinous cystadenoma of the lung}

\author{
A M Davison, J W Lowe, P Da Costa
}

\begin{abstract}
A peripheral nodule in the lung of a 69 year old woman was found on histological examination to contain a focus of adenocarcinoma arising in a mucinous cystadenoma.
\end{abstract}

The recently described mucinous cystadenoma of the lung is a rare lesion with an uncertain natural history. ${ }^{2}$ Carcinomas have been observed in association with various types of lung cyst ${ }^{3}$ but only one arising in a mucinous cystadenoma has been reported. ${ }^{4}$ The clinical and pathological features of a second case are described.

\section{Case history}

A 69 year old woman (a smoker) with a long history of Raynaud's disease and osteoarthritis presented initially with neck pain. This was diagnosed as arthritis but chest radiography performed as part of her investigation showed a peripheral, solitary nodule in the lower zone of the right lung (fig 1). No previous chest radiographs were available for comparison. Cytological examination of sputum showed no abnormality and a chest radiograph two months later showed no change in appearance. There was no relevant past medical history and clinical examination was non-contributory.

\footnotetext{
University

Department of

Pathology, Leeds

General Infirmary,

Leeds LS2 9JT

A M Davison

Department of

Histopathology,

Bradford Royal

Infirmary, Bradford

BD9 6RJ

J W Lowe

Department of

Pathology, Seacroft

Hospital, Leeds

LS14 6UH

P Da Costa

Correspondence to:

Dr A M Davison,

Department of Pathology,

Royal Infirmary, Sunderland SR2 7JE

Accepted 19 September 1991
}

Figure 1 Chest radiograph showing a solitary peripheral nodule in the lower zone of the right lung.
A thoracotomy was performed, at which a cyst $2 \mathrm{~cm}$ in diameter located in the lateral segment of the middle lobe was found to be adhering to the anterior segment of the upper lobe. This wedge of lung tissue was excised.

\section{PATHOLOGICAL FINDINGS}

The wedge of lung tissue, $6 \times 3 \times 2.5 \mathrm{~cm}$, contained a unilocular cyst $2.5 \mathrm{~cm}$ in diameter with light brown gelatinous contents. At one edge of the cyst was a firm pale area $0.3 \times 0.2 \mathrm{~cm}$.

Histologically, the cyst contained mucin and the wall consisted of fibrous tissue (maximum thickness $0.1 \mathrm{~cm}$ ) lined predominantly by a simple, non-ciliated, mucin secreting columnar epithelium occasionally forming small papillary structures that projected into the lumen. Focally the epithelium exhibited a ciliated luminal border. Mucin stains showed a mixture of neutral and acidic mucin in the lumen and alternating sialomucin and sulphomucin in the cytoplasm of the epithelial cells.

The cyst did not communicate with a bronchus and no cartilage or seromucinous glands were observed in the wall.

The firm, pale area consisted of infiltrating glands, the epithelium of which showed nuclear pleomorphism, multilayering of nuclei, increased mitotic activity, and less abundant but more eosinophilic cytoplasm (fig 2). This area of well differentiated adenocarcinoma infiltrated the cyst wall and the adjacent lung parenchyma but did not reach the margin of the excision.

\section{Discussion}

We describe a focus of adenocarcinoma arising in the wall of a lung cyst lined by mucinous epithelium. This type of cyst has recently been described as a mucinous cystadenoma ${ }^{2}$ or mucinous cystic tumour. ${ }^{5}$ Seventeen cases have been reported ${ }^{12-6}$ and clinical details are available in 14 of these patients (nine female, five male). Seven of the 14 cases occurred in the seventh decade of life and at least 10 patients were smokers.

The clinical differential diagnosis includes bronchogenic cyst, congenital adenomatoid malformation, and postinfective bronchogenic cyst. Bronchogenic cysts typically arise in the midline and their wall contains cartilage and seromucinous glands. Congenital adenomatoid malformations tend to occur in the first two years of life, though occasional cases ${ }^{7}$ have been reported in young adults. The wall may contain smooth muscle and the epithelial lining is predominantly of the pseudostratified ciliated columnar-cuboidal type. A postinfective bronchogenic cyst should communicate with a bronchus. 


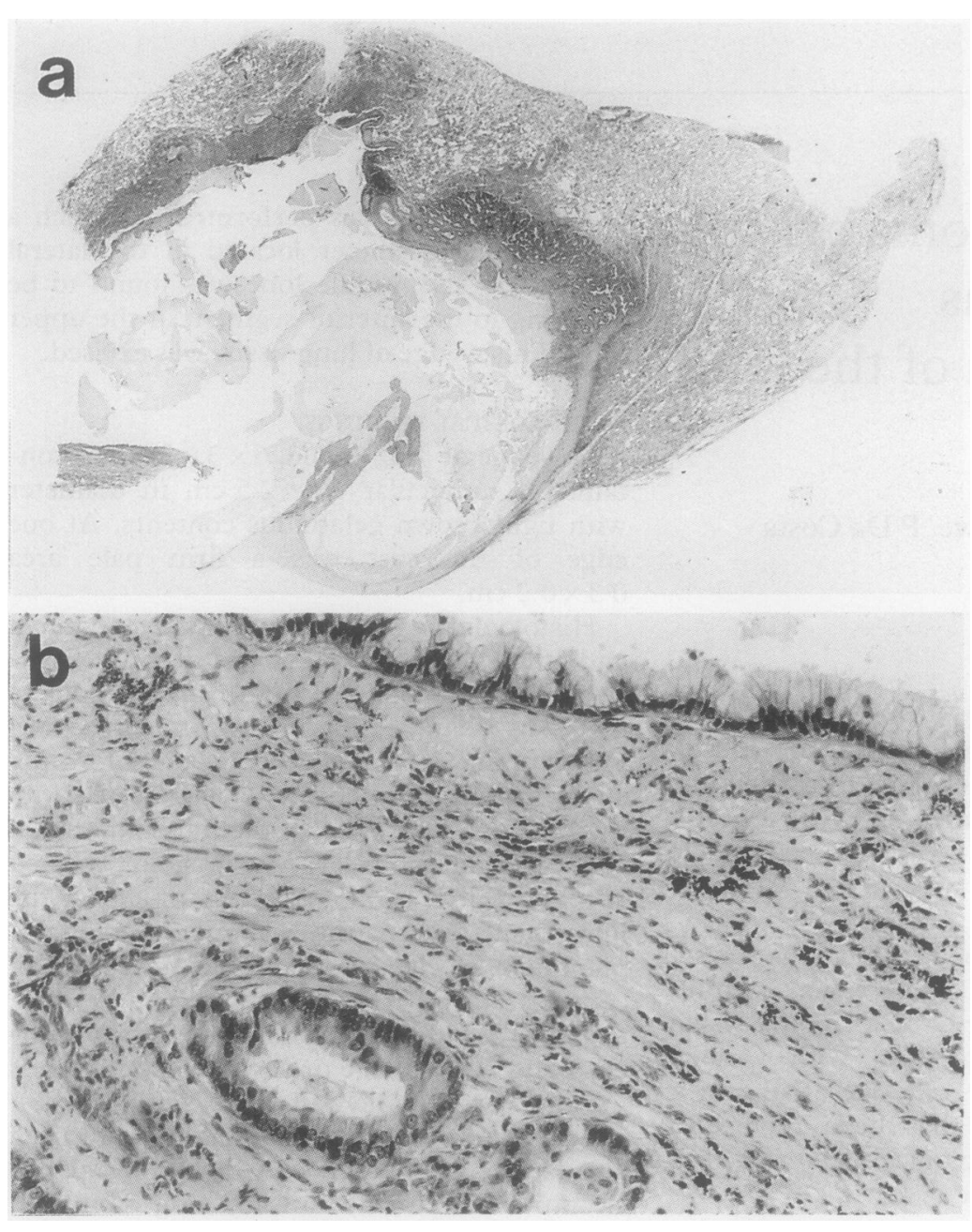

Figure 2 (a) A focus of adenocarcinoma arising in the wall of the cyst (centre of field). (b) Regular mucinous epithelium at the top of the field with a focus of malignant epithelium below showing crowding and multilayering of nuclei with prominent nucleoli.

lesion includes a mucinous bronchioloalveolar carcinoma and a metastatic mucin secreting adenocarcinoma - for example, from the ovary or gastrointestinal tract. This tumour did not have the lepidic growth pattern of a bronchioloalveolar tumour and the appearance of the carcinoma, arising in association with the benign epithelium of the cyst, suggests that this was not a metastatic deposit. The patient remains well more than six months after her initial presentation, and as the malignant focus appears to have been completely removed she probably has a good prognosis.

The fibrous wall indicates the longstanding nature of the cyst, and in a recent review of 12 cases of carcinoma arising in well established cysts $^{3}$ three of the cysts were described as bronchogenic and one as "congenital" (in nine cases the type could not be determined).

Most mucinous cysts of the lung are benign developmental lesions-for example, bronchogenic cyst-and most mucin secreting tumours are conventional adenocarcinomas or bronchioloalveolar cell carcinomas. Cystic mucinous tumours, however, are very rare and have only recently been described. They appear to form a spectrum from benign cystadenomas through borderline malignant lesions to true cystadenocarcinomas, though only one example of this last has previously been reported. ${ }^{4}$ Borderline lesions show some cytological features of malignancy but no convincing evidence of invasion and their important feature is that, although they are not considered to be benign, they appear to have a good prognosis.

This case shows that mucinous lung cysts can become malignant and therefore asymptomatic "coin lesions" should be operated on early and completely excised whenever possible and the specimen submitted to a thorough histological examination.

We would like to thank Mr S Sabanathan (Bradford Roya Infirmary) for permission to publish clinical details, and Mis J I Hamblin for typing the manuscript.

1 Dail DH. Uncommon tumors. In: Dail DH, Hammar SP eds. Pulmonary Pathology. New York: Springer, 1988: 865-6.

2 Kragel PJ, Devaney KO, Meth BM, Linnoila KO, Frierso HF, Travis WD. Mucinous cystadenoma of the lung. Arch Pathol Lab Med 1990;114:1053-6.

3 Prichard MG, Brown PJE, Sterrett GF. Bronchioloalveolar carcinoma arising in longstanding lung cysts. Thorax 1984;39:545-9.

4 Devaney K, Kragel P, Travis W. Mucinous cystadenocarcinoma of the lung: a tumor of low malignant potential [abstract]. Am J Clin Pathol 1989;92:524.

5 Graeme-Cook F, Mark EJ. Pulmonary mucinous cystic tumors of borderline malignancy. Hum Pathol 1991;22: timors 90 .

6 Sambrook Gowar FJ. An unusual mucous cyst of the lung Thorax 1978;33:796-9.

7 Avitabile AM, Hulnick DH, Greco MA, Feiner HD. Congenital cystic adenomatoid malformation of the lung in adults. Am J Surg Pathol 1984;8:193-202. 